\title{
A PROPÓSITO DEL MATRIMONIO CONSULAR EN ESPAÑA DE LA CONTRAYENTE HISPANO-MARROQUÍ Y LA RESOLUCIÓN (41) DE LA DGRN DE 4 DICIEMBRE DE $2018^{*}$
}

\author{
THE RESOLUTION (41 $\left.{ }^{\mathrm{a}}\right)$ OF THE DGRN OF DECEMBER 4, 2018 \\ AND ITS IMPACT ON SPANISH MOROCCAN PARTIES \\ CONTRACTING MARRIAGES IN SPAIN VIA THE CONSULAR \\ FORM
}

\author{
CARMEN RUIZ SUTIL ${ }^{* *}$ \\ Profesora titular de Derecho internacional privado \\ Universidad de Granada \\ ORCID ID: 0000-0001-5063-1845
}

Recibido: 14.05.2020 / Aceptado: 03.06.2020

DOI: https://doi.org/10.20318/cdt.2020.5664

\begin{abstract}
Resumen: La RDGRN (41 ${ }^{\mathrm{a}}$ ) de 4 de diciembre de 2018 se posiciona con la doctrina asentada por dicho Centro Directivo sobre el rechazo de la inscripción del matrimonio celebrado ante Cónsul marroquí radicado en España de la contrayente marroquí naturalizada española, al ser nulo por defecto de forma. Ello evidencia una de las problemáticas derivadas de las situaciones jurídico-familiares que afectan a la población extranjera que adquiere la nacionalidad española, a las que debemos dar respuesta para evitar la inseguridad jurídica y el desconcierto que sufren, en particular, los dobles nacionales hispano-marroquíes.

Palabras clave: matrimonio consular, contrayente hispano-marroquí, renuncia a la nacionalidad anterior, matrimonio islámico celebrado en España.
\end{abstract}

Abstract: The RDGRN (41st) of December 4, 2018 takes a stance for the doctrine established by this same Directive Center, rejecting the registration of the consular marriage based in Spain of a Moroccan spouse who is naturalized Spanish. This marriage is being null due to defect of form. This evidences one of the problems deriving from the legal-family situations that affect the foreign population who takes the Spanish nationality. There is a need of an answer to avoid the legal insecurity and the confusion that particularly Spanish-Moroccan double nationals suffer.

Keywords: consular form marriage, Spanish-Moroccan contracting party, renunciation of the previous nationality, the Islamic marriage conducted in Spain.

Sumario: I. Introducción. II. Adquisición de la nacionalidad española y los efectos de la renuncia a la nacionalidad marroquí. III. El matrimonio de la contrayente hispano-marroquí a la luz de la Resolución de la DGRN de 4 de diciembre de 2018: 1. Matrimonio en España ante autoridad coránica: el desapego de la comunidad hispano-marroquí. 2. Matrimonio consular y el desconcierto originado. IV. Consideraciones finales.

\footnotetext{
*Este trabajo se enmarca dentro del Proyecto de Investigación I+D+i que lleva como título "Movilidad internacional de personas: el impacto jurídico-social en España y en la UE de la adquisición de la nacionalidad española por la población inmigrante", con código DER2016-75573-R.

***uizsuti@ugr.es
} 


\section{Introducción}

1. La población marroquí residente en nuestro país es una de las más significativas desde un punto de vista cuantitativo, debido esencialmente a la proximidad geográfica existente entre ambos Esta$\operatorname{dos}^{1}$ y al considerable aumento de las relaciones de tráfico privado externo. En particular, la Resolución de la Dirección General de los Registros y del Notariado $\left(41^{\mathrm{a}}\right)$ de 4 de diciembre de $2018^{2}$ evidencia una de las cuestiones derivadas de las situaciones que afectan a los extranjeros de origen marroquí que adquieren la nacionalidad española ${ }^{3}$, en la medida en que los actos de estado civil relativos a los naturalizados españoles deben acceder al Registro civil español, aunque se hayan constituidos ante autoridad extranjera. A ello se une la problemática que plantea la doble nacionalidad fáctica, que en el orden práctico provoca que una persona sea española para nuestro país y nacional para su Estado de origen ${ }^{4}$.

2. La práctica reiterada de la Dirección General de los Registros y del Notariado (en adelante DGRN) demuestra que los dobles nacionales hispano-marroquíes van a toparse con ciertos inconvenientes a la hora de inscribir su matrimonio en el Registro civil español ${ }^{5}$.

3. Justamente, esto es lo que se pone de relieve la RDGRN ( $\left.41^{\mathrm{a}}\right)$ de 4 de diciembre de 2018 cuando decreta la invalidez formal del matrimonio celebrado por una marroquí naturalizada española ante Cónsul marroquí acreditado en España, hecho que ha impedido su acceso al Registro civil español ${ }^{6}$. El defecto formal motivó que la DGRN confirmara la no validez de referido enlace por el incumplimiento del art. 49 del Cc por parte de la interesada, al ostentar la nacionalidad española.

4. Para poder evaluar la doctrina vertida en la RDGRN objeto de estudio tendremos que atender a dos cuestiones: en primer lugar, saber si la renuncia exigida para la adquisición de la nacionalidad española tiene consecuencias jurídicas en la pérdida de la nacionalidad de origen marroquí; en segundo lugar, la eficacia del matrimonio de la contrayente hispano-marroquí desde el punto de vista de los ordenamientos español y marroquí.

\section{Adquisición de la nacionalidad española y efectos generados por la renuncia a la nacionalidad marroquí}

5. El que una persona extranjera adquiera la nacionalidad española no evita que en el ámbito del Derecho de familia se generen situaciones jurídicas claudicantes, ya que se puede mantener otra nacionalidad, pese a haber renunciado a la de origen según las exigencia impuestas por el legislador español (art. 23.b Cc) $)^{7}$.

\footnotetext{
${ }^{1}$ Así se desprende de las estadísticas publicadas por el Instituto Nacional de Estadística (INE) sobre extranjeros residentes legalmente en territorio español, donde se refleja que los marroquíes constituyen una de las comunidades de nacionales de terceros Estados con mayor presencia en España. Consúltese http://www.ine.es/.

${ }^{2}$ Publicada $B M J$, año LXXIII, noviembre 2019, núm. 2.224. También se puede consultar en Westlaw-Aranzadi Instituciones (JUR 2019\344313).

${ }^{3}$ En 2018, de un total de 90.828 extranjeros residentes en España que adquirieron la nacionalidad español, la nacionalidad de origen más frecuente fue la marroquí, con 25.372 casos. Estos datos pueden comprobarse en Notas de prensa del Instituto Nacional de Estadística de 11 de junio de 2019, en https://www.ine.es/prensa/aner_2018_p.pdf

${ }^{4}$ Sobre la temática y los distintos presupuestos de la doble nacionalidad fáctica véase S. ADroHer BiosCA, La plurinacionalidad en el Derecho internacional privado español, Madrid, Editorial Reus, 2019, pp. 51-54.

${ }^{5}$ S. Adroher Biosca, "El derecho a contraer matrimonio en la emigración", Migraciones 0, 1996, pp. 107-131.

${ }^{6}$ Con mismo resultado, véase las RDGRN núm. 27/2016 de 28 de octubre 2016 (JUR 2018\102475); RDGRN núm. 14 de 22 de febrero de 2012 (BIMJ, año LXVI, de 7 de noviembre de 2012; RDGRN núm. 4/2004 de 19 enero (JUR 2004\138637); RDGRN núm. 3/2003 de 29 de septiembre (JUR 2004\6146); RDGRN núm. 3/2001 de 23 de octubre (JUR 2002\47692); RDGRN núm. 1/2001 de 28 mayo (RJ 2002\1749).

${ }^{7}$ Se deben hacer algunas matizaciones al requisito de la renuncia, como que los naturales de países iberoamericanos, Andorra, Filipinas, Guinea Ecuatorial, Portugal o los sefardíes originarios de España no están obligados a renunciar a su anterior nacionalidad. Asimismo, existen ciudadanos de países iberoamericanos, ya que tampoco renuncian a su nacionalidad anterior
} 
6. En la RDGRN objeto de este comentario encontramos a una contrayente de origen marroquí que adquirió la nacionalidad española. Generalmente, la población marroquí la obtiene demostrando 10 años de residencia legal en nuestro país, ya que no se encuentra entre los grupos de personas que pueden beneficiarse de una reducción del plazo de residencia de uno, dos o cinco años (art. $22 \mathrm{Cc})^{8}$. El conflicto de nacionalidades surgido en situaciones hispano-marroquíes se debe a que, principalmente, la adquisición de la española depende-como el caso que nos ocupa- del cumplimiento del requisito de la renuncia del art. 23.b Cc, al no impedir la pérdida real de la nacionalidad del país de procedencia.

7. Cada Estado es competente para consentir la renuncia de su nacional, sin limitarse a recibir dicha solicitud ni rechazarla de forma arbitraria9. De esta manera, el ordenamiento marroquí viene permitiendo la renuncia del que adquiere otra nacionalidad, según dispone el art. 19.1 del Código de nacionalidad marroquí ${ }^{10}$. Ahora bien, el interesado tendrá que ser autorizado por decreto a renunciar a sus lazos de origen ${ }^{11}$. No obstante, el principio de vinculación perpetua consagrado por el art. 15 de la Convención de Madrid de 19 de mayo de $1880^{12}$ ampara a todo marroquí que adquiere otra nacionalidad y ser respetado por Marruecos como propio nacional. Y es que el Reino Alauita ha manifestado su reticencia a la renuncia a la nacionalidad de origen marroquí, aunque esté legalmente autorizada en el Código de nacionalidad ${ }^{13}$. Significa, pues, que la renuncia exigida a los nacionales marroquíes para la adquisición de la nacionalidad española no tendrá validez para la autoridad de origen ni tampoco dicha adquisición será un motivo de pérdida de la nacionalidad de aquel país ${ }^{14}$.

8. En consecuencia, nos encontramos con ciudadanos que ostentan una doble nacionalidad anómala o patológica, denominada también de hecho o fáctica, debido a la concurrencia de dos naciona-

porque se amparan en la aplicación de los Convenios de doble nacionalidad. Sobre el tema, véase A. Álvarez RodRíGUEZ, "Derecho de la nacionalidad en España", en R. Rueda Valdivia y Á. Lara Aguado (dirs.), G. Moreno Cordero (coord.), Normativas de nacionalidad en Derecho comparado, Valencia, Tirant lo Blanch, 2020 (en prensa).

${ }^{8}$ Véase R. ViÑas Farré, "Evolución del Derecho de nacionalidad en España: Continuidad y cambios más importantes", Cursos de derecho internacional y relaciones internacionales de Vitoria-Gasteiz, Vitoria-Gasteizko nazioarteko zuzenbide eta nazioarteko herremanen ikastaroak, núm. 1, 2010, pp. 278-313, en espec. p. 301.

${ }^{9}$ Tal y como se desprenden del art. 15.2 de la Declaración Universal de los Derechos Humanos, que establece que "a nadie se privará arbitrariamente de su nacionalidad ni del derecho a cambiar de nacionalidad", así como del art. 8 del Convenio Europeo sobre Nacionalidad de 6 de noviembre 1997, que a pesar que no ha sido ratificado por España, se declara que "cada Estado parte permitirá la renuncia de su nacionalidad, siempre que no se convierta en apátrida y podrá limitar, en su derecho interno, esta renuncia a aquellos caso en que el solicitante viva habitualmente en el extranjero".

${ }^{10}$ La nacionalidad marroquí ha sido regulada por el Dahir $\mathrm{n}^{\circ}$ 1-58-250 de 6 de septiembre de 1958) relativo al Código de la nacionalidad marroquí (Bulletin Officiel $\mathrm{n}^{\circ} 2394$ de 12 de septiembre de 1958, p. 1492), versión consolidada en francés que incorpora las últimas reformas. Vid. https://www.refworld.org/docid/3ae6b5778.html y https://www.refworld.org/cgi-bin/texis/

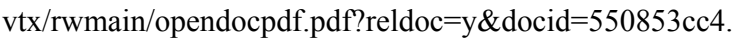

${ }^{11}$ Para renunciar a la nacionalidad marroquí, la persona interesada debe seguir el siguiente procedimiento: 1) presentar una solicitud ante el Ministerio de Justicia en la que declare que renuncia a su nacionalidad marroquí; 2) se requiere la aprobación del gobierno marroquí; 3) se debe emitir un decreto que autorice al interesado a renunciar a la nacionalidad marroquí para su posterior publicación por Decreto en el Boletín Oficial. Véase J. OUHIDA, "Derecho de nacionalidad en Marruecos", en R. Rueda Valdivia y Á. Lara Aguado (dirs.), G. Moreno Cordero (coord.), Normativas de nacionalidad en Derecho comparado, Valencia, Tirant lo Blanch, 2020 (en prensa).

${ }^{12}$ La Conferencia de Madrid de 1880 sobre el Derecho de Protección sobre Marruecos llevó a formalizar acuerdos firmados por este país y ciertos Estados europeos, entre ellos España, para reforzar las ventajas vinculadas al desarrollo en suelo marroquí y ofrecer un marco legal y regulatorio. El texto se puede consultar en https://gallica.bnf.fr/ark:/12148/bpt6k9600646b/f31. image.texteImage.

${ }^{13}$ De hecho, en 2005, Marruecos respondió desfavorablemente a la propuesta holandesa de exigir que los marroquíes inmigrantes de tercera generación en los Países Bajos eligieran obligatoriamente entre la nacionalidad marroquí o la neerlandesa, tal y como confirma J. OUHida, "Derecho de nacionalidad en Marruecos", en R. Rueda Valdivia y Á. Lara Aguado (dirs.), G. Moreno Cordero (coord.), Normativas de nacionalidad..., op. cit.

${ }^{14}$ Por su parte, en Túnez, según se desprende del art. 30 Código de la nacionalidad, la renuncia a la nacionalidad tunecina efectuada por los tunecinos de origen o naturalizados que tengan otra nacionalidad, necesita que sea autorizada por las autoridades mediante decreto del Ministerio de Justicia (arts. 30-32 del Código de la nacionalidad tunecino). Si esto sucede, conlleva la pérdida de la nacionalidad. Por tanto, cabe entender que la renuncia de la nacionalidad tunecina ante la autoridad extranjera no tendrá por sí sola efectos. Al respecto, véase C. Ruiz SutiL, "Derecho de la nacionalidad en Túnez", en R. Rueda Valdivia y Á. Lara Aguado (dirs.), G. Moreno Cordero (coord.), Normativas de nacionalidad en Derecho comparado, Valencia, Tirant lo Blanch, 2020 (en prensa). 
lidades: la adquirida en España y la de origen, dado que la renuncia efectuado ante autoridad española carece de valor Marruecos. Este conflicto de nacionalidades surge debido a las discrepancias entre las ambas legislaciones en cuanto a los principios rectores y a las reglas específicas sobre dicha materia, divergencias que se manifiestan al permitir la adquisición de una nacionalidad española con una renuncia prácticamente simbólica para el ordenamiento español e ineficaz en el sistema marroquí, tal y como ocurre en el supuesto de la RDGN de 4 de diciembre de 2018. Dicho conflicto podría evitarse mediante la elaboración de un Acuerdo de doble nacionalidad entre España y Marruecos que permita que los ciudadanos de ambos países mantener las dos nacionalidades.

9. La efectividad de la renuncia a la nacionalidad originaria viene creando una práctica anómala en determinados Registros civiles españoles ${ }^{15}$. A los ciudadanos marroquíes, tras naturalizarse españoles y antes de la realización del acto de la jura, se les requiere la acreditación por su Consulado de la eficacia de la renuncia a su anterior nacionalidad para proceder a la inscripción registral en España del acta de juramento de adquisición de la nacionalidad ${ }^{16}$. Es evidente que lo único que puede certificar la autoridad consular marroquí es que el interesado sigue siendo nacional del país, y que no pierden tal condición por el hecho de renunciar a su nacionalidad ante autoridad española. Sin embargo, entendemos que la única exigencia que nuestro ordenamiento impone al respecto es que la renuncia tenga lugar ante autoridad española. Por tanto, otros requerimientos diferentes al comentado serían improcedentes, puesto que carecería de respaldo legal en la normativa de nacionalidad (art. 23.b del Cc.). Tal es así que el art. 226 del Reglamento del Registro Civil dispone que sea admitida la declaración de voluntad de renuncia “... aunque no presente documento alguno, siempre que resulte de la declaración la concurrencia de los requisitos exigidos para la adquisición de la nacionalidad...".

10. Desde el punto de vista español, el problema real se suscita cuando la contrayente marroquí que obtiene la nacionalidad española sigue manteniendo vínculos jurídicos-administrativos con su país de origen. En teoría, la nueva nacionalidad genera un vínculo político, jurídico y social con ese Estado. Este lazo también debería abarcar la integración real en las costumbres y el estilo de vida del país de la nacionalidad adquirida. En todo caso, el art. 25.2 a) Cc. manifiesta que, "quien adquiera la nacionalidad española, habiendo renunciado previamente a su anterior nacionalidad, deberá procurar no hacer uso exclusivo de la de origen durante tres años, advirtiendo que podría dar lugar a la privación de la nacionalidad española" ${ }^{17}$.

11. En suma, todas estas circunstancias llevan a que la DGRN, en su Resolución de 4 de diciembre de 2018, resuelva la no inscripción en el Registro civil español del matrimonio consular de la hispano-marroquí, lo que evidencia un claro ejemplo del impacto y de la conexión existente entre las normas de nacionalidad y las situaciones jurídicas relacionadas con el Derecho de familia.

\section{El matrimonio de la contrayente hispano-marroquí a la luz de la Resolución de la DGRN de 4 de diciembre de 2018}

\section{Matrimonio en España ante autoridad coránica: el desapego de la comunidad hispano-marroquí}

12. La condición previa para la celebración del matrimonio en España viene determinada por el la competencia internacional de autoridades recogida en el art. 57 del Cc, según el cual, al menos uno de

\footnotetext{
15 Véase A. P. Rodríguez Bernal, "La renuncia a la nacionalidad de origen en el procedimiento de adquisición de la nacionalidad española: una puerta abierta al fraude de ley", 2011, disponible en: http://rodriguezbernal.com/la-renuncia-a-lanacionalidad-de-origen-en-el-procedimiento-de-adquisicion-de-la-nacionalidad-espanola-una-puerta-abierta-al-fraude-de-ley/ (consultado el 10 de mayo de 2020).

16 Vid. https://legalteam.es/lt/marruecos-se-lava-las-manos-ante-los-requerimientos-de-renuncia-de-nacionalidad-que-esta-haciendo-el-registro-civil-de-barcelona/ (consultado el 10 de mayo de 2020).

17 Vid. A. Álvarez Rodríguez, "Derecho de la nacionalidad en España...”, loc. cit., op. cit.
} 
los contrayentes debe tener su domicilio en España ${ }^{18}$. Dicho límite también debe extenderse a la forma religiosa ${ }^{19}$. La exigencia de domiciliación del alguno de los contrayentes en España implica que, salvo los supuestos autorizados, la celebración de la unión conyugal no podrá concretarse sin haberse tramitado previamente el expediente matrimonial conforme a la legislación del Registro Civil (art. $56 \mathrm{Cc})^{20}$.

13. En cuanto a la celebración en España del enlace conyugal siendo español uno de los contrayentes, solo se admite la forma matrimonial establecida en el art. 49 del Cc y por la doctrina registral de la DGRN ${ }^{21}$. Por tanto, la contrayente de origen marroquí naturalizada española únicamente podrá contraer matrimonio bajo la forma civil ${ }^{22}$ y según las formas religiosas legalmente previstas en nuestro ordenamiento ${ }^{23}$, pero no conforme a las previstas en la ley nacional del otro contrayente marroquí ni ante el Cónsul marroquí acreditado en España. Aclarado este punto, no entendemos el motivo de uno de los fundamentos de derecho de la RDGRN $\left(41^{\mathrm{a}}\right)$ de 4 de diciembre de $2018^{24}$, que lleva a equiparar el tratamiento del caso planteado con el de un matrimonio consular de dos contrayentes extranjeros. El supuesto particular de esta Resolución versa sobre la validez del enlace de una española con un marroquí, lo que excluye cualquier consideración en torno a la forma establecida en el art. $50 \mathrm{Cc}$. De haberse tratado de la unión conyugal entre dos marroquíes, el enlace ante Cónsul sería formalmente válido para la autoridad española.

14. Si ambos contrayentes profesan la religión islámica en el momento de la celebración del matrimonio $^{25}$ podrían haber optado por la forma coránica ${ }^{26}$, al tratarse de una de las religiones contempladas

\footnotetext{
${ }^{18}$ En este sentido, cabe citar la Resolución-Circular de 29 julio de 2005 en la que se declara que "si ninguno de los contrayentes tiene domicilio en España, no existe autoridad competente para instruir el expediente matrimonial previo y el matrimonio no puede celebrarse en España", en Consulta DGRN 23 de diciembre de 2004.

$19 \mathrm{Vid}$. J. C. Fernández Rozas y S. Sánchez Lorenzo, Derecho internacional privado, $11^{\text {a }}$ Edición, Cizur Menor, Cívitas Thomson Reuters, 2020, pp. 458 y ss.; A. L. Calvo Caravaca, J. Carrascosa GonzÁlez, La celebración del matrimonio y sus efectos personales en el Derecho internacional privado (BIB 2015\18072), Grandes Tratados. Tratado de Derecho de la Familia, vol. I, Cizur, Editorial Aranzadi, 2015 (BIB 2015\18063); ID., Derecho internacional privado, vol. II, 18ª edic., Granada Comares, 2018, pp. 82-84.

${ }^{20}$ Este es uno de los nuevos preceptos redactados por la Ley 15/2015, de 2 de julio, de la Jurisdicción Voluntaria con el siguiente texto: "Quienes deseen contraer matrimonio acreditarán previamente en acta o expediente tramitado conforme a la legislación del Registro Civil, que reúnen los requisitos de capacidad y la inexistencia de impedimentos o su dispensa, de acuerdo con lo previsto en este Código. Si alguno de los contrayentes estuviere afectado por deficiencias mentales, intelectuales o sensoriales, se exigirá por el Secretario judicial, Notario, Encargado del Registro Civil o funcionario que tramite el acta o expediente, dictamen médico sobre su aptitud para prestar el consentimiento.

${ }^{21}$ Vid. El Fo Do II de la RDGRN núm. 14 de 22 de febrero de 2012 (BIMJ, año LXVI, de 7 de noviembre de 2012). También esta afirmación se recoge en las RDGRN núm. 47/2014 de 21 febrero (JUR 2014/213481); RDGRN núm. 9/2011 de 3 octubre (JUR 2012\301410); RDGRN núm. 1/2007 de 31 mayo (JUR 2008\263997); RDGRN núm. 4/2004 de 19 enero (JUR 2004\138637).

${ }^{22}$ En el caso del matrimonio civil, la autoridad competente para celebrar el matrimonio podrá ser tanto el secretario judicial, como el notario o el juez de paz o el alcalde del municipio donde se celebre, o sus delegados (art. $51 \mathrm{Cc}$ ). Sobre el tema vid. J. C. Fernández Rozas y S. SÁnchez Lorenzo, Derecho internacional privado ..., op. cit. p. 458.

${ }^{23}$ Las formas previstas por los Acuerdos entre el Estado español y las confesiones religiosas inscritas abren las opciones a los ritos canónico, evangélico, hebraico o islámico. Asimismo, el art. $60.2^{\circ} \mathrm{Cc}$., tras la redacción dada por la Ley 15/2015, de 2 de julio de Jurisdicción Voluntaria (BOE núm. 158, de 3 de julio de 2015), permite la validez de la celebración del matrimonio religioso en la forma religiosa prevista por las iglesias, confesiones, comunidades religiosas o federaciones de las mismas que, inscritas en el Registro de Entidades Religiosas, hayan obtenido el reconocimiento de notorio arraigo en España.

${ }^{24}$ Véase el $\mathrm{F}^{\mathrm{a}} \mathrm{D}^{\mathrm{o}} \mathrm{V}$ de la Resolución comentada. Igualmente ocurre en los $\mathrm{F}^{\mathbf{o}} \mathrm{D}^{\mathrm{o}} \mathrm{IV}$ de la RDGRN núm. 1/2007 de 31 mayo (JUR 2008\263997; de la RDGRN núm. 9/2011 de 3 octubre (JUR\2012\301410) o de la RDGRN de 7 de noviembre de 2005 (BOE núm. 313, de 31 de diciembre de 2005).

${ }^{25}$ La mayor parte de población marroquí en España es de religión musulmana, ya que es la confesión predominante en el país de origen. Existen minorías cristianas y judías, aunque desde 1975, éstas van disminuyendo por el proceso de emigración sufrido en Marruecos. Vid. M. UlloA JimÉNEZ, Entre el Magreb y España. Voces y miradas femeninas, Madrid, ACSUR-Las segobias, 2004, en http://acsur.org/acsur/

${ }^{26}$ Sobre el matrimonio de español y marroquí celebrado por el rito islámico en España, véase la RDGRN núm. 20, de 22 de enero de 2014, BIM, año LXVIII, de 21 de mayo de 2014, pp. 672-674. Entre la literatura española sobre matrimonio islámico, se puede consultar S. AcuÑa, R. Domínguez, P. Lorenzo \& A. Motilla de la CAlle (coord.), El matrimonio islámico y su eficacia en el derecho español, Córdoba, Servicio de Publicaciones de la Universidad de Córdoba, 2003; I. García Rodríguez, La
} 
y admitidas en el ordenamiento español -Ley 26/1992, de 10 de noviembre, por la que se aprueba el Acuerdo de Cooperación del Estado con la Comisión Islámica de España ${ }^{27}$ (en adelante Ley 26/1992)-, en la convicción de que si una persona es de religión musulmana, la ciudadanía y sus creencias religiosas son difícilmente deslindables ${ }^{28}$.

15. El otorgamiento de efectos civiles a los enlaces celebrados en España bajo la forma coránica no conlleva asumir por la ley española todos los mandatos que instituye el Derecho musulmán ${ }^{29}$. La necesidad de nuestro legislador de canalizar esta institución matrimonial, marcada por la discriminación hacia la mujer y la supremacía del varón ${ }^{30}$, originó que la Ley 26/1992 omitiera una serie de requisitos exigidos por la Sharia. Muestra de ello es la ausencia de la exigencia del walí o tutor marital, la omisión del requisito de la dote o la necesidad de celebrar la unión marital ante una autoridad religiosa debidamente acreditada, es decir, de dirigente religioso perteneciente a una comunidad islámica inscrita que forme parte de la Comisión Islámica de España o de alguna de las Federaciones Islámicas integradas en dicha Comisión ${ }^{31}$. Esta última exigencia es totalmente ajena a la Sharia, incluso, a la Mudawana. La intervención ad solemnitatem del cadí o ministro de culto acreditado de la Ley 26/1992 resulta un elemento insólito a la concepción del matrimonio en la ley marroquí, lo que puede conducir a que las autoridades del país vecino rebatan el matrimonio coránico realizado en España. Por ello, no es de extrañar que el colectivo de musulmanes extranjeros instalados en nuestro país eviten el matrimonio islámico conforme la Ley 26/1992.

16. Otra de las cuestiones suscitadas a los contrayentes es conocer si tienen la obligación de tramitar el expediente previo a la unión conyugal conforme al rito que profesa la religión musulmana. Inicialmente, el matrimonio musulmán guarda cierta similitud con el canónico, desplegando efectos civiles desde el momento de su celebración. En un momento posterior, la autoridad civil participa en el trámite de la inscripción del vínculo conyugal para la plena producción de efectos jurídicos ${ }^{32}$. Sin embargo, con la entrada en vigor de la Ley 15/2015, de 2 de julio, de la Jurisdicción Voluntaria ${ }^{33}$, han modificado ciertos aspectos relativos a la

celebración del matrimonio religioso no católico, Madrid, Tecnos, $1^{\text {a }}$ edición, 1999, págs. 223 y ss.; J. A. AlberCA DE CASTRO, "El reconocimiento del matrimonio islámico por el ordenamiento español”, en J. V. GAVAVIDIA SÁNCHEZ (coord.), Inmigración, Familia y Derecho, Madrid, Marcial Pons, 2011, pp. 209-244; A. Fernández-Coronado GonzÁlez, "Matrimonio islámico, orden público y función promocional de los derechos fundamentales", Revista Española de Derecho Constitucional, núm. 85, enero-abril 2009, pp. 125-156; A. NiETo Cruz, "Discriminación de la mujer en el Derecho de familia islámico y orden público", Cuadernos de Derecho Transnacional, vol. 12, núm. 1, Marzo 2020, pp. 286-318.

27 BOE núm. 272, de 12 de noviembre de 1992.

${ }^{28}$ Cfr. Z. Combalía Solís, Recepción del Derecho islámico matrimonial en la jurisprudencia estadounidense, Granada, Comares, 2006, p. 84.

${ }^{29}$ Existen prescripciones coránicas que gozan de plenos efectos jurídicos en el ordenamiento español, mientras que otras, sin ser ilícitas, se limitarán sus efectos a la esfera estrictamente privada y, por último, algunas mandadas o permitidas por la ley islámica son contrarias al orden público español y, por tanto, nulas por la ley española. $C f r$. S. ACUÑa, R. Domínguez, P. LoREnzo \& A. Motilla de la Calle (coord.), El matrimonio islámico..., op. cit. p. 22. También véase M. A. Cebrián Salvavat. "Derechos de inspiración islámica y celebración del matrimonio en España. Problemas de aplicación", Revista electrónica de estudios internacionales (REEI), núm. 34, 2017, pp. 1-50, donde se explica la distinción entre un matrimonio islámico celebrado de acuerdo a una ley extranjera y el matrimonio religioso de tipo coránico como forma de celebración del matrimonio español. A. AzNAR DomINGO y A. Valenzuela Martín, "El matrimonio musulmán y su eficacia en España”, Actualidad Civil, núm. 7-8, julio-agosto 2018.

${ }^{30}$ En algún ordenamiento jurídico de base jurídica musulmana, como sucede en Túnez, se ha interpretado la Sharia en una clave más igualitaria. Así, el Código del Estatuto Personal de Túnez de 1956 introdujo en sus últimas reformas la prohibición de la poligamia y la obligación de prestación del consentimiento matrimonial por ambos cónyuges. Véase a C. RUIZ DE ALMODÓVAR, "El Código Tunecino de Estatuto Personal", Miscelánea de Estudios Árabes y Hebraicos (MEAH), Sección Árabe-Islam, núm. 44, 1995, pp. 157-199; C. Pérez Beltrán, "Una ley en constante evolución: el derecho de familia en Túnez desde la independencia a la actualidad”, Miscelánea de Estudios Árabes y Hebraicos (MEAH), Sección Árabe-Islam, núm. 60, 2011, pp. 235-254.

${ }^{31}$ Para otorgar efectos civiles al matrimonio islámico deberá cumplimentarse los arts. 1, 3 y 7 de la Ley 26/1992, tal y como se afirma en $\mathrm{F}^{\circ} \mathrm{D}^{\circ} \mathrm{V}$ de la RDGNRN núm. 4/2004 de 19 enero (JUR 2004\138637) o en los $\mathrm{F}^{\circ} \mathrm{D}^{\circ}$ IV RDGRN núm. 3/2001 de 23 octubre (JUR 2002\47692); RDGRN núm. 3/2003 de 29 septiembre (JUR 2004\6146) y de la RDGRN núm. 1/2001 de 28 mayo (RJ 2002\1749).

32 Véase P. Orejudo Prieto de los Mozos, La celebración y el reconocimiento de la validez del matrimonio en Derecho Internacional Privado Español, Aranzadi, Pamplona, 2002, p. 33.

${ }^{33}$ BOE núm. 158, de 3 de julio de 2015. 
regulación del matrimonio en forma religiosa ${ }^{34} \mathrm{y}$ que afectan al rito coránico. Especialmente, se prevé que en el momento preciso de la celebración del enlace, el imán o dirigente religioso de la Comunidad Islámica incluya las circunstancias del expediente previo ya tramitado, dándole un plazo de 5 días para la remisión de la certificación de la celebración del mismo al Encargado del Registro Civil competente ${ }^{35}$. A raíz de este cambio, no es posible celebrar el matrimonio islámico sin expediente civil previo y sin aportar el certificado de capacidad matrimonial ${ }^{36}$, lo que sin duda refuerza la seguridad jurídica ${ }^{37}$. No obstante, en este aspecto, la doctrina se mostró dividida ${ }^{38}$, aunque la cuestión quedó ansiada por el art. 4 de la Orden JUS/577/2016, de 19 de abril ${ }^{39}$, que al respecto dispone que el matrimonio religioso conforme el rito coránico “...requiere la tramitación de un acta o expediente previo de capacidad matrimonial, a los efectos de acreditar el cumplimiento de los requisitos de capacidad de los contrayentes y la inexistencia de impedimentos exigidos".

17. No debemos de olvidar que cuando el matrimonio se celebre conforme a la ley española, los cónyuges hispano-marroquíes deben regularizarlo, tal y como dispone los arts. 14-16 de la Mudawana ${ }^{40}$. De esta manera, el acta del matrimonio español deberá ser aportada ante la autoridad consular en un plazo que no exceda de tres meses a partir de la fecha de su celebración (art. 14 del Código de la familia marroquí). Ahora bien, si en dicha acta no constan los dos testigos musulmanes requeridos, los adules titulares de los servicios consulares prepararán un acta complementaria, denominada ishhad mulhaq.

${ }^{34}$ La modificación del art. 7, apartados 2 y 3 del Acuerdo de Cooperación del Estado con la Comisión Islámica de España por la Ley 15/2015, de 2 de julio, de la Jurisdicción Voluntaria, contiene ciertos matices diferentes del matrimonio islámico respecto del evangélico o el israelita. Particularmente, el art. 7 del Anexo dispone que: 1 . Se atribuye efectos civiles al matrimonio celebrado según la forma religiosa establecida en la Ley Islámica, desde el momento de su celebración, si los contrayentes reúnen los requisitos de capacidad exigidos por el Código Civil. Para el pleno reconocimiento de tales efectos, será necesaria la inscripción del matrimonio en el Registro Civil. 2. Las personas que deseen inscribir el matrimonio celebrado en la forma prevista en el número anterior, deberán acreditar previamente su capacidad matrimonial, mediante certificación expedida por el Registro Civil correspondiente. No podrá practicarse la inscripción si se hubiera celebrado el matrimonio transcurridos más de seis meses desde la expedición de dicha certificación.

${ }^{35}$ Por tanto, el aspecto más relevante del contenido de la nueva regulación es que se confirma la existencia de un momento preparatorio, civil, no sólo para los matrimonios evangélico y judío, como ya venía sucediendo desde 1992, sino también para el matrimonio islámico, según la opinión de J. FerRer Ortiz, "El matrimonio de las confesiones religiosas minoritarias en el ordenamiento español”, Revista General de Derecho Canónico y Derecho eclesiástico del Estado, núm. 44, mayo 2017, pp. $1-52$, en espec. p. 38.

${ }^{36}$ En la actualidad, gracias a la Disposición Final $7^{\text {a }}$ de la Ley de Jurisdicción Voluntaria de 2015, se desprende que se alude por primera vez al expediente previo para la inscripción del mismo, tal y como se confirma por R. NAVArRo-VALLS Y A. PANIZO Romo de Arce, "Disposiciones finales quinta, sexta y séptima", en A. FernándeZ de BujÁn (dir.), Comentarios a la Ley 15/20115 de la Jurisdicción Voluntaria, Cizur Menor, Cívitas Thomson Reuters, 2016, pp. 1398-1411; R. García, C. Nieto, M. E., Olmos, L. Ruano, A. García-Garate y M. Alenda, "Informe: La nueva regulación del matrimonio en forma religiosa por la Ley 15/2015, de 12 de julio, de la Jurisdicción Voluntaria (BOE 03-07-2015)", Ars Iuris Salmanticensis, 2015, diciembre, vol. 3, pp. 11-18, en espec. p. 13. Sin embargo, J. Ferrer ORTiz, "El matrimonio de las confesiones religiosas minoritarias...", loc. cit., p. 38, considera la existencia de un error por omisión en el artículo 7.3 de la Ley26/1992, aunque reconoce que en la corrección de errores de la Ley de Jurisdicción Voluntaria, publicada en el BOE núm. 210 del 2 de septiembre de 2015, no llegó a subsanarse este defecto.

${ }^{37}$ Cfr. R. Rodríguez-Chacón, "Régimen jurídico actual del reconocimiento civil e inscripción en el Registro de los matrimonios religiosos no católicos", Estudios Eclesiásticos, vol. 90, 2015, pp. 840-845, donde manifiesta las dificultades que surgen de la celebración del matrimonio islámico sin haber obtenido previamente el certificado de capacidad matrimonial, que suele ser lo habitual. Piénsese que, con semejante regulación, cabría perfectamente la posibilidad de que alguien contraiga más de un matrimonio ante imán o dirigente islámico y elija en un momento dado inscribir uno de ellos, que no tiene por qué ser precisamente el celebrado en primer lugar, dando lugar a posibles situaciones de poligamia.

${ }^{38}$ Existen autores que invocan el primer inciso del art. 7.2 del Acuerdo con la CIE para excepcionar la exigencia del expediente previo para el matrimonio islámico, tales como C. SANCIÑENA AsURMENDI, "Las recientes reformas legales en el sistema matrimonial español”, Ius Canonicum, núm. 56, 2016, pp. 673-674; J. R. Polo SABAU, "Las modificaciones en las formas civil y religiosa de celebración conyugal introducidas por la Ley de la Jurisdicción voluntaria”, en Ma . T. ARECES PIÑOL (coord.), Nuevos modelos de gestión del derecho privado: Jurisdicción voluntaria, Pamplona, Thomson Reuters Aranzadi, 2016, pp. 87-89.

${ }^{39}$ Sobre inscripción en el Registro civil de determinados matrimonios celebrados en forma religiosa y aprobación del modelo de certificado de capacidad matrimonial y de celebración del matrimonio religioso (BOE núm. 97, de 22 de abril de 2016).

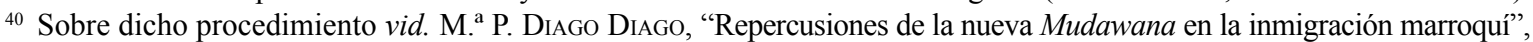
en A. Vicente (edic.), Musulmanes en el Aragón del siglo XXI, Zaragoza, Instituto de Estudios Islámicos y del Oriente Próximo, 2004, pp. 141-167 y en http://www.webislam.com.; ID., "La nueva Mudawana marroquí y el Derecho Internacional privado", REDI, vol. LVI, 2004-2, pp. 1078-1083; M. C. Foblets y M. LouKILI, "Mariage et divorce dans le nouveau code marocain de la famille: quelles implications pour les marocains en Europe?”, Rev. crit. dr. int. priv., vol. III, 2006, pp. 521-555, en espec. pp. $536-539$. 
Esta documentación será remitida al Ministerio de Asuntos Exteriores y de Cooperación Internacional (Dirección de Asuntos Consulares y Sociales). Dicho Ministerio procederá a transmitir la copia al oficial del Registro Civil y a la sección del Juzgado de familia del lugar de nacimiento de cada uno de los cónyuges. Si ambos cónyuges o uno de ellos no hubieran nacido en Marruecos, la copia se envía a la sección del Juzgado de familia de Rabat y al Fiscal del Rey ante el Tribunal de Primera Instancia de Rabat ${ }^{41}$.

18. En definitiva, los inconvenientes derivados de la celebración en España del matrimonio por el rito islámico ocasiona que este tipo de unión sea descartada por la comunidad de hispano-marroquíes, optando por otras posibilidades. Ello nos hace recapacitar sobre nuestra equivocada percepción de vincular a toda la comunidad hispano-marroquí residente en España con la práctica religiosa islámica ${ }^{42}$. Muestra de ello es la poca repercusión del matrimonio coránico, enlace que no termina de satisfacer las expectativas de este colectivo.

\section{Matrimonio consular y el desconcierto originado}

19. La elección de los contrayentes del lugar y la forma de contraer el matrimonio es libre, sin embargo, existen ciertas limitaciones ${ }^{43}$, tal y como ocurre en España. En nuestro ordenamiento, el matrimonio es un acto solemne que exige, como condición de validez, una determinada forma en la manifestación del consentimiento que debe prestarse ante una determinada autoridad y en presencia de testigos ${ }^{44}$. Muestra de ello es la DGRN (41 $\left.{ }^{\mathrm{a}}\right)$ de 4 de diciembre de 2018, que pone en entredicho la validez formal del matrimonio precisamente consular de una española, sin entrar a discutir la capacidad o el consentimiento de los contrayentes.

20. En el caso del matrimonio consular, la competencia del cónsul y, en consecuencia la propia validez formal del matrimonio, viene limitada por las normas de Derecho internacional público, particularmente por el Convenio de Viena de 1963 sobre relaciones consulares ${ }^{45}$. De esta forma, es necesario que se cumplan cuatro requisitos: 1) que la legislación del Estado del Cónsul atribuya a éste último competencia para autorizar la celebración del matrimonio en el extranjero (competencia que, en el caso del Derecho español, le viene reconocida en los artículos $49.1^{\circ}$ y $51.3^{\circ} \mathrm{del} \mathrm{Cc}$ ); 2) que la legislación del Estado receptor de la autoridad consular no se oponga o prohíba el ejercicio de esta función o la competencia en su territorio, tal y como establece el artículo 5 f) del Convenio de Viena y, aun admitiéndola,

\footnotetext{
${ }^{41} \mathrm{http}: / /$ service-public.ma/web/guest/home

${ }^{42}$ Véase J. Moreras, "La religiosidad en contexto migratorio: pertenencias y observancias", en B. López García \& M. Berriane, Atlas de la inmigración marroqui en España. Taller de Estudios Internacionales Mediterráneos TEIM, Madrid, UAM ediciones, 2004, pp. 412-415, autor que confirma dicha afirmación errónea, cuando dispone: “....referirse al componente islámico de los colectivos marroquies es, en primer lugar, suponer que, implícitamente, todas aquellas personas que forman parte de los mismos comparten una misma ritualidad y un mismo sentido de la vida, por no decir que piensen y se comporten de la misma manera. En segundo lugar, dentro del proceso social de atribución de la figura de los marroquies en España, la reciente incorporación del factor religioso viene a completar la serie de atribuciones anteriores, como la socio-económica (trabajador inmigrante), la cultural (árabe-bereber) o la nacional (marroquí)...".

${ }^{43}$ Tal y como podemos observar en P. Orejudo Prieto de los Mozos, "La doctrina de la DGRN en materia de reconocimiento registral de los matrimonios extranjeros, con especial referencia al matrimonio consular", en Derecho registral internacional: homenaje a la memoria del profesor Rafael Arroyo Montero, Madrid, Iprolex, 2003, pp. 275-285, en espec. pp. 280281. Esta autora aclara que, en cuanto al aspecto formal de los matrimonios concluidos en el extranjero, la autoridad española podrá reconocerlos si ha tenido lugar conforme las formas establecidas en el Derecho del territorio de celebración. En todo caso, la validez formal del enlace es motivo de dificultades en la práctica registral, tal y como describe M. GUZMÁn ZAPATER, "Matrimonio celebrados en el extranjeros e inscripción en el Registro Civil: prácticas de la Dirección General de los Registros y del Notariado, Revista Española de Derecho Internacional, 2 vol. 69-2, julio-diciembre 2017, pp. 93-118, en espec. p. 106.

${ }^{4}$ Así lo entiende la Convención sobre el consentimiento para el matrimonio, edad mínima para contraer matrimonio y registros de los mismos abiertos a la firma en la Sede de las Naciones Unidas en Nueva York el día 10 de diciembre de 1962 y adhesión de España a la misma (BOE núm. 128, de 29 de mayo de 1969).

${ }^{45}$ Sobre el tema, véase M. Aguilar Benítez De Lugo, "El matrimonio consular", Boletín del Ministerio de Justicia, año 57, núm. 1937, 2003, pp. 825-850, en espec p. 828.
} 
no la limite a aquellos casos en que ninguno de los contrayentes sea nacional del Estado receptor, como hace España; 3) que al menos uno de los contrayentes sea nacional del país del país del Cónsul, a lo que habría que añadir la exigencia de que éste último se halle domiciliado en la correspondiente demarcación consular (art. $57 \mathrm{Cc}$ ), y 4) que ninguno de los contrayentes sea nacional del país donde el Cónsul ejerce sus funciones. Esta última condición no ha sido cumplimentada en el presente caso, hecho que ha motivado que el Centro Directivo rechace la inscripción del matrimonio concluido ante la autoridad consular marroquí que ejerce sus funciones en España ${ }^{46}$. Al ser la contrayente española, únicamente podía optar por la forma matrimonial civil o religiosa impuesta en el art. $49 \mathrm{Cc}$, a pesar de que pueda ser admitido como válido su enlace matrimonial según la ley de su anterior nacionalidad o, incluso, a la del otro contrayente extranjero.

21. Cuestión distinta sería el momento determinante de la adquisición de la nacionalidad española, ya que si ambos contrayentes fuesen marroquíes en la fecha de celebración del enlace, aunque posteriormente uno de ellos obtuviera la nacionalidad española ${ }^{47}$, tal supuesto no cabría discutir la validez formal del enlace consular ${ }^{48}$.

22. Por último, aunque alejado del supuesto rebatido en la RDGRN objeto de análisis, queremos advertir que el Centro Directivo llega a la consideración de que el enlace conyugal de dos marroquíes concluido ante su autoridad consular es válido, al ser equiparable a la forma del rito islámico prevista conforme a la ley personal, a pesar de no haber intervenido un dirigente religioso acreditado conforme exige el art. 7 de la Ley 26/1992 ${ }^{49}$. En este punto, desde nuestra perspectiva, se yerra por dos motivos. El primero, tal y como ya hemos advertido, no nos hallamos ante un matrimonio entre dos marroquíes, sino entre una española y un marroquí. El segundo, porque la forma religiosa islámica es una manera de celebración del enlace conyugal distinta al matrimonio consular. Conforme a la ley marroquí, un enlace realizado ante Cónsul acreditado en España no es un acto en sí mismo religioso, sino que se acerca más a un acto civil-administrativo ${ }^{50}$. No obstante, desde el punto de vista del ordenamiento español, puede existir cierta incertidumbre, al conservar dicho enlace una base religiosa $^{51}$, como por ejemplo la obligatoriedad de la presencia de dos testigos musulmanes (art. 13.4 de

${ }^{46}$ A pesar de que el matrimonio consular no pudiera ser inscrito en el Registro civil español por no reunir los requisitos para su validez según el Cc o por no haber sido éstos acreditados debidamente, dicho enlace podría ser objeto de anotación con valor meramente informativo (art. 271 RRC). La RDGRN núm. 3/2016 de 19 mayo (JUR 2017\313601), donde las pruebas presentadas en el expediente para la inscripción de un matrimonio de un contrayente hispano-marroquí no justifica suficientemente la "celebración en forma", ya que no resultan ni la fecha, lugar de celebración ni la autoridad que lo autorizó, afirma que si llegan a suministrarse más pruebas, sería factible la inscripción o, en su caso, la anotación del matrimonio.

${ }^{47}$ Este matrimonio debe acceder al Registro Civil, al ser oficiado en territorio español (arts. 1.9 y 15 LRC). Así, según el art. $256 \mathrm{RRC}$, los cónyuges aportarán el certificado expedido por la autoridad o funcionario del país de celebración y el encargado del Registro Civil comprobará que concurren los requisitos legales para ser considerado como un matrimonio válido en España. $C f r$ I. BlÁzquez Rodríguez, "Matrimonio celebrado por rito islámico, certificado de capacidad y Derecho internacional", Cuadernos de Derecho Transnacional, vol. 7, núm. 2, octubre 2015, pp. 382-399, en espec. p. 296.

${ }^{48}$ Tal y como ocurrió en los $\mathrm{F}^{\circ} \mathrm{D}^{\circ}$ IV de la RDGRN núm. 31/2015 de 18 septiembre (JUR 2016\50255) y de la RDGRN núm. 9/2011 de 3 octubre (JUR 2012\301410).

${ }^{49} \mathrm{Vid} . \mathrm{F}^{\mathrm{o}} \mathrm{D}^{\mathrm{o}} \mathrm{V}$ de la RDGRN $\left(41^{\mathrm{a}}\right)$ de 4 de diciembre de 2018. Con semejante afirmación véase los $\mathrm{F}^{\mathrm{o}} \mathrm{D}^{\mathrm{a}} \mathrm{V}$ de la RDGRN núm. 1/2007 de 31 mayo (JUR 2008\263997); de la RDGRN núm. 9/2011 de 3 octubre (JUR\2012\301410) o de la RDGRN de 7 de noviembre de 2005 (BOE núm. 313, de 31 de diciembre de 2005).

${ }^{50} \mathrm{Vid}$. https://www.consulat.ma/fr/etablissement-dun-acte-de-mariage-adoulaire-aupres-des-services-consulaires

${ }^{51}$ Es cierto que, conforme a la ley marroquí, deben cumplirse las exigencias fijadas para el rito coránico, como la presencia de dos "adules" en calidad de testigos legalmente habilitados, la intervención preceptiva del wali o tutor matrimonial de la esposa y el pago de la dote. Cfr. I. Blázquez Rodríguez, "Matrimonio celebrado por rito islámico, certificado de capacidad...", loc. cit., pp. 295-296; ID., "La celebración del matrimonio con elemento extranjero. El caso de los ciudadanos marroquíes", en M. MoYA Escudero (dir.), Familia y sucesiones en las relaciones hispano-marroquies, Valencia, Tirant Lo Blanch, 2015, pp. 71-100, en espec. pp. 92-94. En dicho sentido, véase la doctrina administrativa, tal y como aparece recogida en $\mathrm{el} \mathrm{F}^{\circ} \mathrm{D}^{\circ}$ VI de las RDGRN núm. 31/2015 de 18 septiembre (JUR 2016\50255); RDGRN núm. 170/2016 de 29 agosto (JUR 2018185194) o la RDGRN de 7 de noviembre de 2005 (BOE núm. 313, de 31 de diciembre de 2005). En este último supuesto, la DGRN comprueba mediante el conocimiento de la Mudawana, donde no se impone la intervención preceptiva ad solemnitatem del cadí o ministro de culto, pero sí es necesaria la presencia del adul. En consecuencia, se considera que el matrimonio consular ha producido efectos desde su fecha, por lo que estima el recurso y revoca el auto apelado que denegaba la inscripción del matrimonio. 
la Mudawana) o la invocación a $A l-l a \bar{h}$ en la lectura del acta matrimonial ${ }^{52}$, requisitos que originan la confusión comentada.

\section{Consideraciones finales}

23. La doctrina de la DGRN relativa a la no validez formal del matrimonio consular de los naturalizados españoles, obligados por nuestras normas a renunciar a su nacionalidad de origen, es constante. En este sentido, la Resolución de 4 de diciembre de 2018 se pronuncia sobre varios aspectos: en primer lugar, en relación con las distintas formas en las que un español puede contraer matrimonio (art. $49 \mathrm{del} \mathrm{Cc}$ ), excluye definitivamente la posibilidad de que este pueda celebrarse ante Cónsul extranjero acreditado por España, ya que se trataría de una unión matrimonial nula por defecto de forma (art. 73 Cc). En segundo lugar, el enlace consular concluido en dichas circunstancias, no cabe su inscripción en el Registro Civil español.

24. En el orden práctico, hemos comprobado que la doble nacionalidad fáctica viene generando disfunciones derivadas de la exigencia de renuncia previa a la nacionalidad de origen impuesta por el derecho español. Esta renuncia, aunque válida para nuestra autoridad, puede ser meramente simbólica para el ordenamiento jurídico del marroquí que pretende nacionalizarse español, que seguirá manteniendo la nacionalidad de país vecino a cualquier efecto.

25. Compartimos la opinión de $\operatorname{Spiro}^{53}$ en cuanto a la actual admisión de la plurinacionalidad como derecho fundamental del ciudadano en la era de la globalización, siempre que sea expresión de su autonomía de la voluntad y que no represente ninguna amenaza sustancial a los intereses de los Estados. En este sentido, una solución de lege ferenda que propone la doctrina española ${ }^{54}$ es adecuar nuestra legislación de nacionalidad a la realidad migratoria. Particularmente, la modificación se centraría en suprimir el requisito de renuncia a la nacionalidad de origen cuando se adquiere la española, lo que reduciría la problemática que conlleva doble nacionalidad de hecho.

26. Por otra parte, queremos evidenciar la poca incidencia de celebraciones de matrimonios conforme al rito islámico de la Ley 26/1992 por parte de la población hispano-marroquí residente en España. A pesar de que es una figura plenamente aceptada y asentada en nuestro país, tanto a nivel legislativo como en la propia sociedad, de la práctica administrativa de la DGRN se desprende la poca repercusión para el colectivo hispano-marroquí de la celebración del matrimonio en forma coránica instaurado por la ley española. Ello es debido a los inconvenientes que conlleva la eficacia del mismo a la luz del ordenamiento jurídico marroquí, unido a la obligatoriedad del trámite del expediente previo matrimonial que acredite la capacidad matrimonial, conditio sine qua non de la reforma de la Ley de Jurisdicción Voluntaria de 2015. En consecuencia, estos dobles nacionales suelen decantarse por otras soluciones.

27. Mientras llegan respuestas que mejoren la situación que acabamos de describir, consideramos la conveniencia de que el colectivo de hispano-marroquíes sea informado adecuadamente para evitar la frustración que produce las situaciones claudicantes, tal y como está sucediendo con los enlaces consulares de los contrayentes marroquíes que han adquirido la nacionalidad española. De ahí nuestra insistencia en la necesidad de que las Administraciones y autoridades de ambos países adviertan a sus dobles nacionales de las relaciones jurídicas vinculadas a los varios ordenamientos implicados.

\footnotetext{
${ }^{52}$ Sobre ello véase M. C. Feria García, "La traducción de actas matrimoniales marroquíes", en https://www.academia. edu/1540907/La_traducci\%C3\%B3n_jurada_de_actas_matrimoniales_marroqu\%C3\%ADes?auto=downloadpp, pp. 221-258, en espec. pp. $229-230$.

${ }_{53}$ P.J. SPIRo, "Dual citizenship as human right", International Journal of Constitutional Law, Volume 8, Issue 1, January 2010, pp. 111-130, https://doi.org/10.1093/icon/mop035

${ }^{54}$ Vid. S. Adroher Biosca, La plurinacionalidad en el Derecho internacional..., op. cit. p. 53 y los autores de Estados Unidos citados en la nota 93.
} 